\title{
THE EFFECT OF GENDER ON INDIVIDUAL INVESTMENT DECISIONS
}

\author{
DOI: 10.17261/Pressacademia.2021.1494 \\ PAP- V.14-2021(20)-p.97-101
}

\section{Elmas Ozturk}

Istanbul Commerce University, School of Finance, Capital Markets Department, Istanbul, Turkey. elmasoztrk@hotmail.com, ORCID: 0000-0002-9294-437X

\section{To cite this document}

Ozturk, E. (2021). The effect of gender on individual investment decisions. PressAcademia Procedia (PAP), 14, 97-101.

Permanent link to this document: http://doi.org/10.17261/Pressacademia.2021.1494

Copyright: Published by PressAcademia and limited licensed re-use rights only.

\section{ABSTRACT}

Purpose- Investment decisions differ in the face of the demographic characteristics of the investors, their economic conditions and their level of knowledge about the financial developments they are in. Gender identity plays a role in helping to answer questions about investment decisions. For this reason, the purpose of the study is to define how female and male investors differ in their individual investment preferences.

Methodology- In order to investigate the gender differences in individual investment decisions, Turkey was taken as a basis in the study. The survey method was used in the study to access the investors' information. Cross tables and hypotheses were generated based on the data obtained. The chi-square test was applied to test whether there is a difference between male and female investors' perceptions of investment behavior. The calculated chi-square value was compared with $10 \%$ significance level.

Findings- As a result of the hypothesis findings, it was determined that gender caused a significant difference on investment decisions. Differences are observed between male and female investors in terms of financial decisions such as the risk dimension of the investment, the variety of investment instruments and the investment process.

Conclusion- As a result of the analysis; Male investors prefer riskier investments than female investors. While male investors tend to invest primarily in stocks, female investors tend to invest in gold.

Keywords: Portfolio management, demographics, risk tolerance, individual investor, investment decisions JEL Codes: C12, C42, G32

\section{CINSIYETIN BIREYSEL YATIRIM KARARLARINA ETKISI}

\section{ÖZET}

Amaç- Yatırımcıların demografik özellikleri, ekonomik koşulları ve içinde bulundukları finansal gelişmelere ilişkin bilgi seviyeleri karşısında yatırım kararları farklılaşmaktadır. Cinsiyet kimliği, yatırım kararları ile ilgili soruları cevaplamaya yardımcı nitelikte rol oynamaktadır. Bu nedenle çalışmanın amacı, kadın ve erkek yatırımcıların bireysel yatırım tercihlerinde nasıl farklıık gösterdiğini tespit etmektir.

Yöntem- Bireysel yatııım kararlarındaki cinsiyet farkılıklarını analiz etmek için çalışmada Türkiye baz alınmıştır. Yatırımcıların bilgisine ulaşmak için araştırmada anket yöntemi kullanılmıştır. Elde edilen veriler doğrultusunda çapraz tablolar ve hipotezler oluşturulmuştur. Erkek ve kadın yatırımcıların yatırım davranışına ilişkin konulardaki tercihleri arasında farklılaşma olup olmadığını test etmek için ki-kare testi uygulanmıştır. Hesaplanan ki-kare değeri \%10 anlamlılık düzeyi ile karşılaştırılmıştır.

Bulgular- Hipotez bulguları sonucunda cinsiyetin, yatırım kararları üzerinde anlamlı bir farkılığa neden olduğu tespit edilmiştir. Kadın ve erkek yatırımcılar arasında yatırımın risk boyutu, yatırım araçlarının çeşitliliği ve yatırımın süreci gibi finansal kararlar açısından farklıık gözlenmektedir.

Sonuç- Analiz sonucunda; erkek yatırımcılar, kadın yatırımcılara oranla daha riskli yatırımları tercih etmektedir. Erkek yatırımcılar, öncelikli olarak hisse senedi yatırımına yönelirken kadın yatırımcılar altın yatırım aracına yönelmektedir.

Anahtar Kelimeler: Portföy yönetimi, demografik özellikler, risk toleransı, bireysel yatırımcı, yatırım kararları.

JEL Codes: C12, C42, G32

\section{GiRiş}

Bireyler, tüketimlerinden artan gelirleri ile piyasalarda işlem yapmaktadır. Genel itibari ile bu işleme yatırım, bu işlemi kendi amaçları doğrultusunda gerçekleştirenlere bireysel yatırımcı denilmektedir. Bireysel yatırımcılar için yatırımlarının kendi amaçları karşısında başarılı 
olması ve yatırımcıyı tatmin etmesi önemlidir. Genellikle bu amaç, yatırımcının kısa zamanda en düşük risk ile en yüksek getiriye sahip olmasıdır. Bireysel yatırımcıların tasarruflarını değerlendirmesi sonucunda, dönemsel kazançlara ya da kayıplara sahip olması kararların doğru alınması gerektiğini ortaya koymaktadır. Elde ettikleri tasarrufları amaçları doğrultusunda yatırımlara yönlendiren bireysel yatırımcıların hangi yatırım aracını tercih ettiği, hangi düzeyde riski kabul ettiği, hangi faktörlerden etkilendiği gibi konularda doğru stratejileri izlemesi gerekmektedir.

Bireysel yatıımcıların sahip oldukları sermayeyi korumak, değerini artırmak ve devamlı getiri sağlamak amacıyla finansal piyasalarda yatırım yapma kararları birçok faktör tarafından kısıtlanmakta ve yönlendirilmektedir. Yatırım yapmak isteyen birey, bu işlemi gerçekleştirirken birçok faktörü göz önünde bulundurmak zorundadır. Her faktör, yatırımcıları aynı oranda etkilemez, yatırımcıların özelliklerine göre faktörler değer kazanır ya da değer kaybeder. Bu noktada cinsiyet faktörü, yatırım kararları ile ilgili soruları cevaplamaya yardımcı nitelikte rol oynamaktadır. Erkeklerin ve kadınların yaşam sürecinde oynadıkları farklı roller ve bu rollerin etkisi, kişisel seçimlerinden finansal kararlarına kadar pek çok alana yansımaktadır. Günümüzde finansal piyasalarda aktif rol oynayan kadın yatırımcı sayısı artmaktadır. Daha sağlıklı bir finansal piyasa yorumu için erkek ve kadın yatırımcılar arasındaki yatırım tercihleri ile ilgili olası farklılıkların tespit edilmesi önemlidir. Yapılan bu çalışma kapsamında; tasarruf sahiplerinin cinsiyet etkenine bağlı olarak değişkenlik gösteren portföy tercihleri hakkında bilgi sahibi olmak amaçlanmıştır. Bu amaç doğrultusunda çalışmada, öncelikle literatürde yer alan örnek çalışmalara, ikinci olarak çalışmada kullanılan veri ile yönteme, son olarak çalışma sonucunda erişilen bulgulara ve bulguların analizlerine yer verilmiştir.

\section{LITERATÜR}

Cinsiyetin, bireysel yatırımcıların yatırım tercihlerini nasıl etkilediğine yönelik çeşitli araştırmalar literatürde yer almaktadır. Bu araştırmalar örneklem grubunun, zamanın ve küresel gelişmelerin değişmesi ile birlikte farklı sonuçlar öngörmektedir Bu çalışmada, günümüzde kadınların yatırım alanında geçmişe kıyasla daha fazla yer alması nedeniyle kadın ve erkek yatırımcılar arasındaki farklılaşma incelenmek istenmiştir. Bu yönüyle, literatüre katkı sağlaması amaçlanmıştır.

Literatürde genellikle kadın ve erkek yatırımcıların riske bakış açısı ele alınmıştır. Yapılan çalışmaların büyük bir çoğunluğu sonucunda kadınların erkeklere oranla daha az riski tercih ettikleri varsayılmıştır. Grabble ve Lyton (1998) yaptıkları çalışmada, bireysel yatırımcıların riske bakış açısını demografik etkenlere göre farklılaşmasını incelemiştir ve araştırma sonucunda erkek yatırımcıların kadın yatırımcılara kıyasla riski daha fazla kabul ettiği kanısına varmıştır. Aynı görüşü savunan bir başka çalışma ise Kahyaoğlu tarafından gerçekleştirilmiştir. Kahyaoğlu (2011) hisse senedi alım satım işlemlerine ilişkin 31 bireysel yatırımcı ile gerçekleştirdiği çalışmasında, kadın yatırımcıların yatırımlardaki risk algısı erkek yatırımcılara oranla daha yüksek olduğunu ve bu nedenle, riski tercih etmediklerini tespit etmiştir. Benzer şekilde çalışmalarında, yatırımcıları risk toleransına göre sınıflandırmak için kullanılan en önemli demografik değişkenlerden birinin cinsiyet faktörü olduğunu açıklayan Anbar ve Eker (2009), araştırma sonucunda kadınların risk toleransının erkeklere göre daha zayıf olduğunu belirtmiştir. Gümüş ve arkadaşları (2013), bireysel yatırımcılara ait demografik özelliklerin yatırım kararları üzerindeki etkisini Türk ve Azeri yatırımcılar örneklemi ile inceleyen bir çalışma gerçekleştirmiştir. Araştırma sonucunda, cinsiyet değişkeninin yatırımcılar arasındaki farklılaşmanın nedeni olduğunu belirtmiştir. Kadın yatırımcıların genellikle daha fazla riskten kaçındığını ve yatırım araçları arasından en fazla gayrimenkul yatırımlarına yöneldiğini tespit etmiştir. Çankaya ve arkadaşları (2013) çalışmalarında, Türkiye'de farklı risk tutumlarının cinsiyete bağlı değişimini üniversite öğrencileri üzerinde incelemiştir. Genç katılımcıların riske bakış açılarının ve bu yöndeki davranışlarının incelendiği çalışmada, kadın katılımcıların genel olarak erkek katılımcılara kıyasla riskten kaçan bir profil sergiledikleri görülmektedir. Alpay ve arkadaşları (2015), aylık en az 7.000 TL geliri olan ve Samsun ilinde ikamet eden yatırımcılar üzerine bir araştırma gerçekleştirmiştir. Araştırma kapsamında kadın ve erkek yatırımcıların portföylerine bakıldığında, risk seviyesi düşük yatırım enstrümanlarının kadın yatırımcıların portföylerinde erkek yatırımcılara göre daha fazla yer aldığı görülmüştür. Doğukanlı ve Önal (2000), Adana'da gerçekleştirdiği çalışmalarında, kadın yatırımcıların portföylerinde riskli görülen hisse senetlerinin erkek yatırımcılara oranla daha az yer verdiği görülmüştür. Jianakoplos ve Bernasek (1998) çalışmalarında ABD örneklemi üzerinde çalışmış ve kadın yatırımcıların erkek yatırımcılara kıyasla daha fazla riskten kaçtığını açıklamıştır. Hawley ve Fuji (1993), Döm (2003), Küçüksille (2004), Emektar (2007), Ceyhan (2008) da aynı görüşe destek veren çalışmalara yer vermiştir ve araştırmalarında erkek yatırımcıların kadın yatırımcılara kıyasla daha fazla riske yatırımlarında yer verdiklerini öngörmüştür. Bu çalışmalar ışığında erkeklerin riski daha fazla tolere edebilmesinin iki temel nedeni olduğu varsayılmıştır. Bunlardan ilki, gelir durumu faktörüdür. Gelir durumu yatırımcıların katlanabildiği risk seviyesini arttırabilecek bir etken olarak tespit edilmiştir. İkinci temel neden ise finansal bilgi donanımından kaynaklanmaktadır. Kadın yatırımcıların erkek yatırımcılara oranla daha az gelir düzeyine ve finansal bilgi donanımına sahip olması daha düşük risk seviyesini kabul etmelerine neden olmaktadır (Karan ve Tanyolac, 2016).

Literatürde çoğunluk görüşün cinsiyet faktörünün yatırım kararları üzerinde etkili olduğunu savunmasına rağmen karşıt görüşlerde yer almaktadır. Embrey ve Fox (1997), cinsiyet etkeninin yatırım tercihleri üzerindeki etkilerini araştırmıştır. Araştırmaları sonucunda, cinsiyet faktörünün, yatırım araçlarının seçimi gibi yatırımcı kararları üzerinde önemli bir etkisinin görülmediğini açıklamışlardır. Aynı görüşe destek veren Masters(1989), Grable ve Joo (1999), Hanna ve arkadaşları (2001) çalışmalarında cinsiyet faktörünün riskten kaçınma açısından bir etken olmadığını ve yatırımcılar arasında bu faktörün bir farklılaşmaya sebebiyet vermediğini açıklamışlardır. Yapılan çalışmalar doğrultusunda cinsiyet açısından yatırımcılar ele alındığında, kadın ve erkek yatırımcı arasında farklılaşan bir diğer sonuç ise işlem sıklığı ve işlem hacmidir. Yapılan çalışmalar sonucunda, erkek yatırımcıların piyasada daha fazla yer aldığını ve kadın yatırımcılara oranla daha çok işlem yaptıkları görülmüştür. 2001 yılında yapılan bir çalışmada Barber ve Odeon, "erkekler kadınlardan daha çok işlem yaparlar" hipotezlerini test etmiştir. Çalışmanın sonucunda, erkek yatırımcıların kadın yatırımcılardan \%45 oranında daha fazla işlem yaptıkları ortaya konulmuştur. Aynı görüşü destekleyen Kahyaoğlu, 2011 yılında yatırım kararlarında cinsiyetin rolünü ortaya koyduğu araştırmasında; erkek yatırımcıların kadın yatırımcılara göre daha sık işlem yaptığını ve erkek yatırımcıların işlem hacminin de kadın yatırımcılara göre daha yüksek olduğunu tespit etmiştir. 


\section{VERI VE YÖNTEM}

Yatırımcıların cinsiyeti ile yatırım tercihleri arasındaki ilişkinin belirlenmesi amacıyla çalışmada anket yöntemi uygulanmıştır. 24 sorunun yer aldığı ankette öncelikle yatırımcıların özelliklerini belirleyen yaş, cinsiyet, eğitim durumu gibi demografik sorulara, daha sonra finansal durumunu belirleyen gelir durumu, yatırım miktarı gibi sorulara ve son olarak yatırım süreci boyunca sergiledikleri davranışları ölçmeyi sağlayan yatırım aracı tercihi, riske bakış açısı gibi sorulara yer verilmiştir. Anket çalışmasının örneklem grubunu Türkiye'de yer alan bireysel yatırımcılar oluşturmaktadır. Çalışmanın kapsamını genişletmek ve bireysel yatırımcılar hakkında daha fazla bilgiye ulaşabilmek amacıyla ankete katılan yatırımcı sayısı arttırılmaya çalışımıştır. Bu nedenle anket, hem internet üzerinden hem de yüz yüze olacak şekilde yatırımcılar ile paylaşılmıştır. Sonuç olarak 508 yatırımcının verisine ulaşılmıştır. Elde edilen anket verileri istatistiksel yazılım paketi SPSS kullanılarak analiz edilip yorumlanmış ve hipotezlerin sonuçları değerlendirilmiştir. Buna ek olarak, hipotezleri test etmek için istatistik metot olarak kikare test yöntemi kullanılmıştır.

\section{BULGULAR}

$H_{0}=$ Yatırımcıların cinsiyetleri ile yatırım kararları arasında farklılık yoktur.

$H_{1}=$ Yatırımcıların cinsiyetleri ile yatırım kararları arasında farklılık vardır.

Table 1: Kurgulanan Hipotezlerin Ki-kare Değerleri

\begin{tabular}{|c|c|c|}
\hline N:508 (Bireysel Yatırımcı) & $X^{2}$ & Sign. \\
\hline Aylık Yatırım Tutarı & 57.234 & $0.001 * * *$ \\
\hline Yıllık Yatırım Yüzdesi & 30.163 & $0.001 * * *$ \\
\hline Dini Görüş Etkisi & 3.449 & $0.063 *$ \\
\hline Finans Eğitimi & 33.303 & $0.001 * * *$ \\
\hline Yatırım Aracı Sayısı & 9.052 & $0.060 *$ \\
\hline Portföy Çeşitlendirmesi & 34.564 & $0.001 * * *$ \\
\hline Yatırım Aracı Tercihi & 71.837 & $0.001 * * *$ \\
\hline Risk Tercihi & 85.343 & $0.001^{* * *}$ \\
\hline Getirisi ve Riski Yüksek Yatırım Tercihi & 50.994 & $0.001 * * *$ \\
\hline Borsa Yatırımı & 83.659 & $0.001 * * *$ \\
\hline Yatırımın Amacı & 17.548 & $0.001^{* * *}$ \\
\hline Portföy Büyüklüğü & 59.481 & $0.001 * * *$ \\
\hline Portföy Yönetim Süresi & 36.440 & $0.001 * * *$ \\
\hline Elde Tutma Süresi & 36.136 & $0.001 * * *$ \\
\hline Portföy Revizyon Sıklığı & 33.912 & $0.001 * * *$ \\
\hline Portföy Kontrol Sıklığı & 62.537 & $0.001 * * *$ \\
\hline Finansal Gelişmelerin Takibi & 94.141 & $0.001 * * *$ \\
\hline
\end{tabular}

*Anlamlılık düzeyi *** \%1, ** \%5 ve * \%10’a göre kabul edilmiştir.

Hipotez bulguları sonucunda cinsiyetin yatırım kararları üzerinde anlamlı bir farklılık olduğu tespit edilmiştir. Çalışmanın analiz bulguları şu şekildedir; kadın ve erkek yatırımcılar arasında aylık yatırım miktarı bakımında anlamlı bir fark tespit edilmiştir. Kadın yatırımcıların geneli, aylık küçük miktarlarda (1-500 TL) yatııımlarını gerçekleştirirken erkek yatırımcılar daha büyük miktarlarda (1001-2500 TL) yatırım 
gerçekleştirmektedir. Aynı şekilde, yıl bazında yatırımcıların yatırım miktarını incelediğimizde; kadın yatırımcılar, erkek yatırımcılara kıyasla yıllık daha az yatırım yapmaktadır.

Kadın ve erkek yatırımcılar arasında dini görüş bakımından anlamlı bir fark tespit edilmiştir. Kadın yatırımcılar yatırım kararlarını verirken erkek yatırımcılara kıyasla dini ögelerden daha fazla etkilenmektedir. Kadın ve erkek yatıımcılar arasında finansal eğitim bakımından anlamlı bir fark tespit edilmiştir. Erkek yatırımcıların finansal açıdan bilgi donanımları kadınlardan daha fazladır. Kadın ve erkek yatırımcılar arasında portföylerini kaç tane yatırım aracı ile çeşitlendirdikleri konusunda anlamlı bir fark tespit edilmiştir. Kadın yatırımcıların çoğunluğu tek tip yatırım aracı ile yatırımlarını gerçekleştirirken erkek yatırımcıların çoğunluğu portföylerinde daha fazla yatırım aracına yer vermektedir. Kadın yatırımcıların geneli portföylerinde bir tane yatııı aracına yer verirken erkek yatırımcıların geneli üç tane yatııım aracını tercih etmektedir.

Kadın ve erkek yatırımcılar arasında riske bakış bakımından anlamlı bir fark tespit edilmiştir. Kadın yatırımcılar yatırım kararlarını düşük riskle sınırlandırırken, erkek yatırımcılar bu konuda daha toleranslıdır. Erkek yatırımcılar, riski ve getirisi yüksek yatırımları tercih ederken, kadın yatırımcılar bunun yerine riski ve getirisi düşük yatırımları tercih etmektedir. Kadın ve erkek yatırımcılar arasında yatırım aracı tercihi bakımından anlamlı bir fark tespit edilmiştir. Kadın yatırımcılar altın yatırım aracını tercih ederken erkek yatırımcılar hisse senedini tercih etmektedir. Kadın ve erkek yatırımcılar arasında borsada yatırımlarını gerçekleştirme bakımından anlamlı bir fark tespit edilmiştir. Kadın yatırımcılar borsada yatıımlarını gerçekleştirme fikrine uzak durmaktadır. Kadın ve erkek yatırımcılar arasında yatıııları gerçekleştirme amacı bakımından anlamlı bir fark tespit edilmiştir. Kadın yatırımcılar sermayelerini korumak isterken erkek yatırımcılar yüksek getiri amacıyla yatırımlarına yön vermektedir.

Kadın ve erkek yatırımcılar arasında portföy büyüklükleri bakımından anlamlı bir fark tespit edilmiștir. Kadın yatırımcılar küçük miktarda (0$5000 \mathrm{TL})$ portföyleri yönetirken erkek yatırımcılar daha büyük miktarda (100.000 TL üzeri) portföyleri yönetmektedir. Kadın ve erkek yatırımcılar arasında portföy yönetim süresi bakımından anlamlı bir fark tespit edilmiştir. Kadın yatırımcılar 1 yıldan kısa sürede yatırımlarını yönetirken erkek yatırımcılar 5 yıldan uzun sürede yatırımlarını yönetmektedir. Kadın ve erkek yatırımcılar arasında yatırımları elde tutma süresi bakımından anlamlı bir fark tespit edilmiştir. Kadın yatırımcılar bir yatırım aracını 1 yıldan uzun süre boyunca portföylerinde tutarken, erkek yatırımcılar ortalama 1 ile 3 ay içerisinde bir yatırım aracı üzerinde işlem gerçekleştirmektedir.

Kadın ve erkek yatırımcılar arasında portföy kontrolü bakımından anlamlı bir fark tespit edilmiştir. Kadın yatırımcılar ayda bir portföylerinin performansını incelerken erkek yatırımcılar günlük olarak bu alışkanlıklarını gerçekleştirmektedir. Aynı şekilde, portföy revizyonu açısından da kadın ve erkek yatırımcılar arasında fark gözlemlenmektedir. Kadın yatırımcılar erkek yatırımcılara kıyasla daha uzun aralıklarla bu işlemi gerçekleştirmektedir.

\section{SONUÇ}

Yatırımcılar portföylerini oluştururken şahsi özelliklerine bağlı kalarak kararlarını gerçekleştirmektedir. Yaşam boyu değişen ihtiyaçları ve beklentileri doğrultusunda aldıkları kararlar sahip oldukları doğuştan gelen faktörler çerçevesinde farklılık göstermektedir. Aynı kriterlere sahip yatırımcılar yatırım kararlarını alırken eşgüdümlü davranışlar gerçekleştirmektedir. Çalışmadan elde edilen bulgular anket katılımcılarının cinsiyetine göre büyük ölçüde farklılık göstermektedir.

Analiz sonuçları incelendiğinde, cinsiyet faktörünün öncelikle riske bakış açısı bakımından etkisi ortaya çıkmaktadır. Kadın yatırımcılar erkek yatırımcılara kıyasla daha az risk sever konumundadır. Nitekim literatürde yer alan erkek yatırımcıların kadın yatırımcılara oranla yatırımlarında daha fazla riske yer verdiği çoğunluk görüşü desteklemektedir. Ayrıca, daha önce çalışmalarında bu görüşe yer veren Ede (2007), Küçüksille (2004), Anbar ve Eker (2009) çalışmaları ile örtüşmektedir. Bir başka farklılık portföy çeşitlendirmesinde karşımıza çıkmaktadır. Tek tip yatırım aracı ile portföylerini oluşturan kadın yatırımcıların portföy büyüklükleri de çoğunlukla küçük miktarlardan oluşmaktadır. Kadın yatırımcıların aksine erkek yatırımcılar daha büyük miktardaki portföyleri yatırım araçlarını çeşitlendirerek yönetmektedir. Aydın ve Ağan (2016) çalışmaları ile doğrusal kadın yatırımcıların büyük bir çoğunluğu altın yatırım aracını tercih etmektedir. Erkek yatırımcılar ise tercihlerinde hisse senedine ağırlık vermektedir. Kadın yatırımcılar ile erkek yatırımcıların ayrıldığı bir diğer noktada portföylerinde yer alan yatırım araçlarını elde tutma süresidir. Kadın yatırımcıların portföylerindeki yatırım araçlarının alım satım süresi erkek yatırımcılara kıyasla daha uzundur. Erkek yatırımcılar portföylerindeki yatırım araçlarını daha kısa sürede al sat yapabilmektedir. Kadın yatırımcıların çoğunluğunun finansal piyasalardaki tecrübe süresinin erkek yatırımcılardan daha kısa olması ve kadın yatırımcıların yatıııları için ayırdıkları miktarın erkek yatırımcılardan daha az olması bu sonuca neden olabilmektedir. Kısaca, Kahyaoğlu'nun (2011) araştırmasında yer verdiği gibi daha yüksek işlem hacmine sahip erkek yatırımcılar, kadın yatırımcılara göre daha sık işlem yapmaktadır. Beklenenin aksine, kadın yatırımcılar portföylerini erkek yatırımcılara göre daha az sayıda yatırım aracı ile çeşitlendirmektedir.

Geçmiş çalışmalarla paralel sonuçların yer aldığı çalışmamızda, kadın yatıımııların yatırım alanında daha aktif rol oynaması gerektiği sonucu ortaya çıkmaktadır. Gerek finans alanındaki eksik donanımları gerek ise gelir durumlarının kısıtı olması nedeniyle arka planda kalan kadın yatırımcıların bu konuda desteklenmesi gerekmektedir. Kadın yatırımcıların bilgi donanımının geliştirilmesi durumunda; aktif yatırımcı sayısında gerçekleşecek artışın yanı sıra piyasadaki işlem hacminin de pozitif etkileneceği beklenmektedir.

\section{KAYNAKÇA}

Alpay E. E.- Yavuz M, \& Kahyaoğlu M. B. (2015). Gelir Durumunun Risk Algisina Etki Eden Değer Sosyo-ekonomik ve Demografik Faktörler Üzerindeki Etkisi. C.Ü. İktisadi ve İdari Bilimler Dergisi, 16( 1), 205-226.

Anbar, A. \& Eker, M. (2009). Bireysel Yatırımcıların Finansal Risk Algılamalarını Etkileyen Demografik ve Sosyoekonomik Faktörler. ZKÜ Sosyal Bilimler Dergisi, 5(9), 129-150. 
Aydın, Ü. \& Ağan, B. (2016). Rasyonel Olmayan Kararların Finansal Yatırım Tercihleri Üzerindeki Etkisi: Davranışsal Finans Çerçevesinde Bir Uygulama. Ekonomik ve Sosyal Araştırmalar Dergisi, 12( 2), 95-112.

Barber, B. M. \& Odean, T. (2001). Boys will be Boys: Gender, Overconfidence, and Common Stock Investment, The Quarterly Journal of Economics, 116(1), 261-292.

Ceyhan, G. (2008). Yaşam Biçimlerinin Finansal Risk Toleransına Olan Etkileri Üzerine Bir Uygulama, Yayınlanmamış Yüksek Lisans Tezi, Hacettepe Üniversitesi, Sosyal Bilimler Enstitüsü, Ankara.

Çankaya, S. \& Ucal, M. \& - O’neil M. (2013). Nothing Ventured Nothing Gained: Gender Differences In Fınancial Risk Behavior Among Turkish University Students. International Journal of Economics and Finance Studies, 5(1),322-334.

Doğukanlı, H. \& Önal, Y. B.(2000). Adana İli Kapsamında Hisse Senedi Yatırımcıları Profilinin ve Hisse Senedine Yatırım Kararlarında Etkili Olan Faktörlerin Araştırılması", Çukurova Üniversitesi Sosyal Bilimler Enstitüsü Dergisi, 6(6), 185-209.

Döm, S. (2003). Yatırımcı Psikolojisi, İstanbul, Değişim Yayınları.

Ede, M. (2007). Davranışsal Finans ve Bireysel Yatırımcı Davranışları Üzerine Ampirik Bir Uygulama, Basılmamış Yüksek Lisans Tezi, Marmara Üniversitesi Bankacılık ve Sigortacılık Enstitüsü, İstanbul.

Embrey, L. L.\& Fox, J. J.(1997). Gender Differences in the Investment Decision-Making Process. Financial Counseling and Planning, 8(2), 3340 .

Emektar, B.(2007). Pay Senedi Piyasasında Bireysel Yatııımcı Davranışlarını Belirleyen Güdüler ve IMKB'de Bir Uygulama, Yayınlanmamış Yüksek Lisans Tezi, Kocaeli Üniversitesi, Sosyal Bilimler Enstitüsü, Kocaeli.

Gümüş, F.B.\& Koç, M. \& Agalarova, M.(2013). Bireysel Yatırımcıların Yatırım Kararları Üzerinde Etkili Olan Demografik ve Psikolojik Faktörlerin Tespiti Üzerine Bir Çalışma: Türkiye ve Azerbaycan Uygulaması. KAÜ iỉBF Dergisi, 4(6), 71-93.

Grable, J.E. \& Lytton, R.H. (1998). Investor Risk Tolerance: Testing the Efficacy of Demographics as Differentiating and Classifying Factors. Financial Counseling and Planning, 9(1), 61-73.

Grable, J.E. \& Joo, S. (1999). Factors Related to Risk Tolerance: A Further Examination. Consumer Interests Annual, 45, 53-58.

Hanna, S. D. \& Gutter, M. S. \& Fan, J. X. (2001). A Measure Of Risk Tolerance Based on Economic Theory. Financial Counseling and Planning, $12,53-60$.

Hawley, C. B. \& Fujii E. T. (1993). An Empirical Analysis of Preferences for Financial Risk: Further Evidence on the Friedman-Savage Model. Journal of Post Keynesian Economics, 16, 197-204.

Jianakoplos, N. A. \& Bernasek, A. (1998). Are Women More Risk Averse? Economic Inquiry, 36(4), 620-630.

Kahyaoğlu, M. B. (2011). Yatırım Kararlarına Etki Eden Çeşitli Duygusal ve Psikolojik Faktörlere Maruz Kalma Düzeyi Üzerinde Cinsiyetin Rolü: İmkb Bireysel Hisse Senedi Yatırımcıları Üzerine Bir Uygulama. Ekonomik ve Sosyal Araştırmalar Dergisi, 7(1), $29-51$.

Küçüksille, E. (2004). Optimal Portföy Oluşturmaya Davranışsal Bir Yaklaşım, Yayınlanmamış Yüksek Lisans Tezi, Süleyman Demirel Üniversitesi, Sosyal Bilimler Enstitüsü, Isparta.

Masters, R. (1989). Study Examines Investors' Risk Taking Propensities. Journal of Financial Planning, 2(3), $151-155$.

Tanyolac, C. \& Karan, M. B. (2016). Analyzing Demographic Characteristics of The Security Investors: An Application to Turkey. Journal of Economics, Finance and Accounting, 2(4), 680-703. 